\title{
Psychological intervention to enhance the volitional quality of perseverance in athletes with hearing impairment
}

\begin{abstract}
The work addresses a topic of great importance for the development of the sprinter which constitutes one of the areas of Athletics, the king of sports. The Santiago de Cuba Province has provided excellent athletes, of which the Academia de Santiago de Cuba category 14 - 15 (school) stand out; due to the results achieved in national competitions despite the shortcomings detected in their psychological preparation, considering it necessary to improve the process of training volitional qualities with a view to the conscious preparation of athletes and the responsibility assumed when having to win demanding training loads. The objective pursued with this research is the development of an intervention plan to enhance the quality of volitional perseverance in athletes with hearing impairment. As a result, intervention activities are provided that integrate the psychological with the practical, thus establishing the dialectical unit to achieve the development of individual qualities during the development of training.
\end{abstract}

Volume 13 Issue 3 - 202 I

\author{
Lic. Julio Cesar Cobas Román,' Dr C Alina \\ Bestard Revilla ${ }^{2}$ \\ 'P. Inst Sports Medicine. S. Cuba \\ ${ }^{2} \mathrm{PT}$. Eastern University, Cuba
}

Correspondence: Dr C Alina Bestard Revilla, PT. Eastern

University, Cuba, Email abestard@uo.edu.cu

Received: April 27, 202I | Published: June II, 202 I

Keywords: volitional quality, perseverance, hearing impairment, sprinter

\section{Introduction}

Currently, sports training has become a complex activity, which requires an approach from multiple disciplines, where psychology is also integrated into the contributions from various spheres of knowledge, since each time the aspects contemplated by physical, technical and tactics are more even, being the psychological aspects that make the difference. ${ }^{1}$

In sports, and especially athletics, perseverance is very important for the achievement of concentration and the successful realization of competitive results. The feeling of emotional control provides the individual with psychic stability, as well as personal security, which makes him more capable of responding to the demands of the environment. ${ }^{2,3}$

Perseverance is a quality common to people of strong character, many of them leaders in their field of action, far from being intimidated face of difficulties or the hardship, vaunting and redoubling their efforts with great determination to achieve the real goals that have been set. It is what one is proposed to achieve, in moments in which one intends to reach an end defined by himself, it is that before achievement on which man relies to be part of a life with perseverance in his own questioning. It is something that one proposes for oneself, thus motivating this virtue known as perseverance and leading it to a satisfaction or something already achieved.

Therefore, delving into the study of perseverance as a volitional quality becomes a core issue in the field of research applied to sports psychology. In this sense, it is pointed out that psychological intervention in this quality must have an educational nature that encourages behavior modifications and prepares athletes to act in challenging conditions. It coincides with the proposals of several authors who value the importance of this issue, within the psychological preparation in sports training., ${ }^{2,-10}$ Therefore, it is necessary to design effective strategies to establish objectives that significantly enhance perseverance in athletes, to increase their results in competitions.
Perseverance, which could be equated with perseverance or tenacity, is one of the most important elements when it comes to achieving success in any goal. There is a Chinese proverb that illustrates the importance of this quality: "If you fall seven times, get up eight." Miguel de Unamuno used to say: "The way to hit the nail once is to hit the horseshoe a hundred times."

In adolescence, an age that is also included within the school sports category, it appears as a result of a process of reflection, assessment and aspirations that the athlete has; takes on a special connotation since it is at this stage where self-assessment develops, in which the opinion that others have about the adolescent exerts great influence, it is for this reason that it is essential to take into account the particularities of the conditions of the social situation of development, given the need to prepare the athlete not only for the demands of sport but also for the healthy development of their personality. ${ }^{11}$

As a sample of all the above, it was found that the athletics team for the hearing impaired of the school category (14-15) of the Sports Initiation School (EIDE) "Captain Orestes Acosta" of the Provincial Academy of the province of Santiago de Cuba, during the school games of 2017 and 2018, although the 1st place was reached, results were obtained below the desired forecasts.

During the analysis of the training plan planned for the next macro-training cycle, as well as in the systematic evaluations inherent to the psychologist-coach relationship, it was verified that among the problems found, among other existing causes, the athletes did not make the necessary effort in the execution of physical exercise, they do not persist in meeting the goal set during training and athletes are not systematic in training. This situation was maintained in the following training period (2018), so it was decided to prioritize attention in particular to the volitional quality of perseverance. A state of instability of this quality can undermine sports results.

Therefore, there is an urgent need to apply psychological interventions aimed at enhancing it in training. 
The objective of this research is aimed at developing a psychological intervention plan to promote the willful quality of perseverance, in Athletics athletes, speed area, with hearing impairment category 1415 years of the Provincial Academy of Santiago de Cuba.

It is specified as a field of action: The volitional quality of perseverance in athletes with hearing disabilities in the speed area of the Athletics Academy.

\section{Materials and methods}

To carry out the research, a mixed methodology was used; qualitative-quantitative; being a descriptive cross-sectional investigation. Which was developed with 6 athletes with hearing disabilities from the 14-15 category athletics sport, in the speed area of the Provincial Academy of Santiago de Cuba belonging to the EIDE "Captain Orestes Acosta", in the period corresponding to the macrocycle training 2017 - 2018. in the same diagnosis it was performed in the volitional quality perseverance during practice and watched or how it affected the performance of these athletes. Subsequently, a psychological intervention plan is developed and applied. P ara again diagnose and assess their effectiveness, taking into account the psychological characteristics of people with hearing disabilities, how it influences the manifestations of perseverance in these athletes.

Taking into account the object of study of said research, techniques such as observations, interviews with athletes and coaches were applied, as well as the psychological tests Grid Random Number Table , Psychological Performance Inventory, Volitional qualities test, sports motives test, test IDARE, temperament test and review of documents and teaching program adapted coaches for athletes with disabilities.

\section{Results and discussion}

To analyze the value of volitional qualities in sports training, some opinions of various authors such as Rodionov, ${ }^{12}$ must be taken into consideration, regarding the attitude towards initiative, which is nothing more than the ability to adopt with ease the initiative by own impulse with the consideration of the intellectual data, without waiting for a stimulus that comes from outside. As can be seen, this quality can be manifested in a general sense in the behavior of the subjects, in isolated situations within the sporting activity or in some sports such as Chess. In addition, this can be seen reflected through other qualities such as autonomy and independence. Even Rudick ${ }^{13}$ calls it on the same level, independence and initiative.

On the other hand, psychologists sport often use some conceptual devices that facilitate the understanding of the meaning of volitional qualities by coaches and athletes, example is: courage, fighting spirit, combativeness, decision, the perseverance, among others, that contain a high semantic content, especially within this area, in whose voice any of the dimensions indicated later is implicit. ${ }^{14-16}$

It is not possible to achieve the objectives demanded by high-level sport or sporting excellence without the presence of these qualities. As the athlete moves through the high performance pyramid, they face greater physical, psychological and social demands. Therefore, to be able to climb to the most significant sporting results, it is necessary to show an adequate development of these qualities and to know how to express them in the moments that it deserves.

During the trainings of the athletics team for the disabled in the category (14-15) of the Provincial Academy of the Centro Único
"Capitán Orestes Acosta" in Santiago de Cuba, it was observed that the coaches did not define the objectives to be achieved together with the athletes. In each session, an explanation of the objective, purpose and importance of each type of exercise was not made, so they were not a source of motivation for them.

The workouts turned out to be monotonous as a result of the repetition of each exercise without the coach systematically perceiving the progress in its performance, praise was not given when the exercises were performed correctly, rather errors were reinforced without taking into account an assessment of trainer-athlete set of where they had occurred and how to correct the technique for its proper performance, sometimes when the trainer was not supervising the training, the athletes did not perform the amount of exercises that had been dosed, to finish quickly so the exercises Finals were made without the required technical quality. ${ }^{17-20}$

Loss of concentration was manifested in athletes, coordination of movements sometimes despite their hearing problem, they talked a lot among themselves in their own language and they were not attentive to the signals directed by the coach. When they were required by the coach they made gestures of disgust, which adopted a posture of disinterest towards the activity.

The training climate was unfavorable between them and the coach himself created by the authoritarian figure, taking into account the methodological form applied by him, where they were not the most appropriate, he also made comparisons between athletes, which undermines sports performance, focus on the achievement and fulfillment of objectives in the athlete himself, generating reduction in volitional qualities perseverance in the performance of technical exercises.

In the training sessions, the lack of concern on the part of the athletes themselves was evidenced by not correcting the mistakes made during the activity, no matter how simple it may be, fundamentally in the performance of the first exercise of each modality, where its successful performance generates more confidence and athlete safety.

Both in competitions and competitive modeling, the presence of this fear of failure had a negative influence on the sports performance of the athletes, since they did not concentrate adequately to carry out the lifts (mainly the first lift), they made mistakes during the execution (they performed the lifts well in advance without taking advantage of the regulated time to achieve a good concentration) and adopted a negative attitude to the non-successful completion of the lift.

The athletes who did not achieve the successful completion of the lifts manifested in them a high level of tension, anxiety, and more fear of failure, generating more insecurity, nervousness, using verbal expressions referring to stop trying again and negative and defeatist thoughts regarding it to his personal worth..$^{21,22}$

The demands of the coaches, the presence of parents, peers, the public and the refereeing influenced the loss of control of this fear of failure, which contributed to the existence of difficulties in achieving concentration of attention by changing the focus of attention easily, feeling pressured by fear of failing and being judged by others, especially by people significant to them, generating performance anxiety, which negatively affected the effectiveness of the action and its proper performance. Taking into account the need to train athletes with resources or tools that allow them an adequate management and control of this fear of failure, a plan of psychological actions is proposed that will contribute to the adequate management and control of this fear based on optimization. sports performance. 
The action plan had as objectives:

i. Train the coaches, athletes and family with respect to the theoretical aspects related to the fear of failure, as well as the methods and techniques used for its management and control.

ii. Provide a space that enhances self-knowledge in athletes, reflecting on what are the attitudes, beliefs and thoughts that generate the fear of failure and that hinder the achievement of adequate sports performance.

iii. Provide resources or tools to athletes, which facilitate the management and control of the fear of failure both in the sports field and in the different areas of their development.

This psychological action plan is characterized by its open, flexible, participatory, group, practical and experiential nature. The techniques used allow both athletes and coaches to reflect, dialogue, share and analyze based on their own reality and experiences, in an entertaining and motivating way that arouses and maintains interest.

This plan of psychological actions included 4 fundamental actions that were carried out during the entire macrocycle, they are designed to work in sessions, with a frequency of 2 times a week, with a duration of approximately 45 minutes. The number of activities is flexible, considering that a greater number of them may be needed to internalize the required skills. The sessions were worked with the athletes, coaches, families and jointly. Each of them has its own objective, the methods, techniques, materials to be used and the frequency of its implementation. ${ }^{23-27}$

\section{Section I}

Name: Orientation to success.

Objective: To promote the formation and maintenance of an orientation for the achievement of success.

\section{Developing:}

Be part of participatory techniques. How am I? How do I want to be? After the athlete raises how he is considered in the field of sport, the coach makes an assessment and establishes a sports ideal of great athletes who have achieved success in this form of athletics, so that the athlete at the end of training makes a comparison and establishes as he would like to be through the parameters indicated by the coach.

i. It is recommended to apply this technique at the beginning of the training session and at the end of it, taking into account the number of athletes it has, in order to allow the exchange and opinions of the athletes.

ii. Make prolonged efforts without pause, where the athlete learns to maintain the effort at the same level despite fatigue.

\section{Section 2}

Name: My sports, healthy and instructive physical activity.

Objective: Promote aid, conducting collective analyzes of individual results.

\section{Developing:}

First, the coach will give them a brief explanation about what they will see in the program. Which will deal with the importance of training for competition, its usefulness, taking into account the quality of being persistent. At the end, they will be asked questions on the subject and criteria will be exchanged with them in order to observe what they propose to solve a better result during training. This will be held once a week, and students will be seated in the classroom or on the field with the coach for viewing.

i. Closing technique: consists of the student with a word expressing how he felt during the activity.

\section{Section 3}

Name: Technique for sensitization

Objective: To contribute to the awareness of athletes about the role that corresponds to play to enter training with optimism and effort.

Development: Reading of the article "The dancer" (Annex \# 6)

Objective: To sensitize athletes within the personal attitudes essential to face life.

The following orders must be fulfilled

i. Reading and analysis of the comic, this will be indicated as an independent homework task

ii. The coach will be able to use different variants so that it reaches the group, according to their material conditions: the computer, hand out a sheet containing each student, orient them by team.

iii. At the beginning of the training session, an assessment of the content will be carried out through an entertaining dialogue that allows students to reach personal conclusions from the exchange.

This technique has the purpose of contributing to the awareness of athletes about the role that corresponds to play to enter the training with optimism and effort Provoke in the athlete the aspiration to fulfill the proposed task until the end, motivating him and giving him security, creating situations Competitive tasks where more difficult tasks than the usual developer are proposed, which requires each of them to put into practice a series of traits such as: independence, respect, collaboration, responsibility, tolerance and specifically perseverance.

\section{Section 4}

Name: I educate myself

Objective: Promote individual and / or team analysis to establish commitments based on setting achievement goals.

Development: perseverance as a favorable condition to overcome physical and mental exhaustion for it:

i. Use additional loads in training, that is, after complying with those planned, presenting others in an unexpected way and with greater demands.

ii. Show the athlete that he can fulfill the assigned task, for the level of demand that volitional efforts require, but it should not be excessively high that it seems impossible to fulfill it.

iii. To provoke in the athlete the aspiration to fulfill the proposed task until the end, motivating him and giving him security, creating competitive situations where more difficult tasks than the usual ones are proposed.

Propose, from the training for the competitions, tasks in which the athletes face obstacles, objective and subjective with different levels of difficulty during the process of special psychological preparation.

i. Carry out training sessions in different sports facilities with the public, which constitute unusual conditions. 
At the end of the training, the coach must perform the closing technique (how I am going) and record each day in what condition the athlete is at the end of the training.

The group dynamics allows the individual self-knowledge of the athletes and the team from the reflection and identification of the main difficulties that exist in the group, in terms of the quality of perseverance, it favors the development of interpersonal relationships in them.

\section{Section 5}

Name: I if I can.

Objective: To educate the athlete how to use the verbal component of the movement through self-injunctions. Development: the teacher must explain the initial task in detail through sequences, videos, and other materials.

i. Complete the motor representation in the logical-verbal component (theoretical explanations).

ii. Demonstrate movement slowly (Slow pace).

iii. Numerous exercises with adequate correction.

iv. Use of volitional verbal score (example, this is the moment, now, I jump in, Correct the performance in the internal plane (image) and externally.

v. Ideo-motor training (when there is some experience). Not to be confused with visualization where there are no serious errors.

vi. Start the difficult action to overcome tiredness (fatigue). Through self- command language for mobilizing readiness and performance capabilities.

vii. Specialized literature (in school teams about technique).

Solve tasks in the shortest possible time spent during decision making, enabling greater concentration and mobilization of efforts.

i. The description of the movement before they execute. This serves as a guide.

Explanation-demonstration together to make it more effective.

i. The teacher must record the behavior of the athletes and make it known in a systematic way so that they know where they must overcome the obstacles to overcome.

\section{Section 6}

Name: Compete and you will win

Objective: To strengthen the quality of perseverance in athletes, during training for competitions, creating an environment of satisfaction and security.

\section{Developing}

i. Solve problematic game situations, where athletes can choose between two or three possible responses, independently, in a competitive way, to stimulate creativity and the flexible nature of the tactical plan.

ii. Encourage the best results in game problem solutions.

iii. Carry out discussions on the importance of the competition as well as the real possibilities of the team and the opponents, highlighting the weak and strong points when informing: iv. The level of preparation to increase security and confidence when mobilizing the potential of the team in general and the athlete in particular.

v. Results obtained through sports debate videos, to stimulate interests and intentions, in such a way as to avoid or overcome negative experiences (failure), by developing pleasure, desire, taste and enjoyment when training and competing.

vi. It is necessary to present the athlete with distant goals, prospects, even the highest order goals, no matter how great the successes the athlete has achieved, it is necessary to constantly instill in him the idea that the result achieved is far from his possibilities real, that immediately after the goal reached a new, higher and great perspective is proposed.

vii. Play competitive games within the team with the aim of developing the rivalry and sporting aggressiveness so necessary in this sport.

\section{Section 7}

Name: The value of the competition.

Objective: Promote the development of the ability to critically assess the execution of their actions and plan the following

Development: during the special psychological preparation, the ability to assess and execute their actions, through the fighting spirit indicator.

i. Develop clarity of sensations, perceptions and representations of movement, visual, auditory, tactile. Ask the athlete the oral reproduction corresponding to the movement image, after the information obtained the corresponding mental and real exercise is carried out.

ii. To train and expand the athletes' special senses of value, such as the directions for the executive regulation of movements.

iii. Raise offensive or defensive tactical situations either individually or in teams, and that they solve it according to their response levels, with this we achieve independence.

iv. Ask for several alternative answers in order to perfect the technique.

These actions will favor the cognitive affective development of the athletes for a better performance in the competition.

\section{Conclusions}

i. Volitional qualities are of great significance to form an optimal state of psychic disposition and are essential in the process of general psychological preparation.

ii. The theoretical, documentary and psychological analysis carried out in this study reveals that the volitional quality of perseverance in athletes with hearing disabilities is of great importance in their sports performance by allowing them to overcome negative experiences (failure) and develop pleasure, desire, taste and enjoyment for training and competition.

iii. From the diagnosis made to these athletes with hearing disabilities, the deficiencies that existed in them regarding this quality were verified and that prevented them from achieving better sports performance.

iv. An action plan was developed that evidently contributed to the education of volitional qualities, specifically perseverance 
in Athletics athletes, in order to obtain excellent competitive results.

\section{Acknowledgments}

None.

\section{Conflicts of interest}

The author declares no conflicts of interest.

\section{Funding}

None.

\section{References}

1. International Tennis Federation. Manual for Advanced Trainers. Canada: ITF Editorial. 2012.

2. García Ucha FE. Psychological tools for coaches and athletes. Havana: Editorial Sport. 2004.

3. Sánchez Acosta ME, M González García. Psychological Tools for coaches and athletes. Havana, Editorial Sports. 2004.

4. Rodríguez Guerra E. With Mind and Heart. Sports psychology. Puerto Rico: First Book Publishing. 2000.

5. Sánchez Acosta ME. The psychological preparation of the athlete Colombia: Editorial Kinesis. 2002.

6. González Carballido LG. The athlete's emotional response: A scientific view of behavior in the face of competitive challenge. L a Habana, Editorial Sports. 2004.

7. Casadesús Schumann J. Some fundamental qualities of temperament for the sporting performance of elite wrestling athletes. Havana: Editorial Sports. 2003.

8. Calviño M. Dynamic behavior analysis. Havana, Editorial Félix Varela 2002.

9. Sánchez Acosta ME. And other authors. Psychology of training and sports competitions. Havana, Editorial Sports. 2005.

10. Cañizares Hernández M. Psychology in physical activity. Its application in physical education, sports, recreation and rehabilitation. Havana: Editorial Sports. 2008.

11. Domínguez García L. Developmental psychology: adolescence and youth Selection of readings, Havana, Editorial Félix Varela. 2003.
12. Rodionov AV. Psychology of sports confrontation. Havana: Editorial ORBE. 1981.

13. Rudik PA. Psychological characteristic of psychological activity. In Psychology. Text book. Higher Institute of Physical Culture of Havana. Moscow: Editorial Planeta. 1990.

14. Lane AM. Sport and exercise psychology. London. Editorial Hodder Education. 2008.

15. Sainz de la Torre N. Psychopedagogy of Physical Education and School Sports. Havana: Editorial Sports. 2010.

16. Aránguiz Paredes RE. Psychopedagogical intervention plan to enhance the volitional sphere in swimmers category 13-14 years of the EIDE "Cerro Pelado" of Camagüey. Thesis to apply for the Bachelor's Degree in Physical Education and Sports. EIEFD, Mayabeque, Cuba. 2011.

17. Loforte MI. Psychopedagogical actions to increase the state of mental disposition of the men's basketball team of the Faculty of Physical Culture in Santiago de Cuba. Thesis to obtain the title of Master in Sports Psychology. UCCFD Havana. 2008.

18. Naples, NN. Psychopedagogical strategy to develop volitional qualities during training in Athletics athletes, Speed area, category 14-15 years of the Provincial Academy of Santiago de Cuba. Tes is to defend Diploma in Sport Psychology. Eastern University. 2012.

19. Sánchez Acosta ME, M González García. General Developmental Psychology. Havana, Editorial Sports. 2004.

20. González Carballido LG. Internal conditions and sports activity. Variables of essential consideration in psychological preparation. 2001.

21. González Carballido LG. Importance of stress as an object of study in sports psychology. 2001.

22. González Carballido LG. A practical approach to sport psychology. 2001

23. Casales Fernández JC. Basic knowledge of social psychology. Havana Editorial Félix Varela. 2004

24. Russian Corral R. History of psychology. Notes for your study. Havana, Editorial Félix Varela. 2003

25. Bello Dávila Z, JC Casales Fernández. Social psychology. La Habana Editorial Felix Varela. 2003

26. http://www.efdeportes.com

27. Antelo E. Set of psycho-educational actions to contribute to the formation of volitional qualities during training. Thesis for the title of Master Psychology of the sport. University of the East. 2009. 